\title{
Application of HEC-HMS for flood forecasting in hazara catchment Pakistan, south Asia
}

\begin{abstract}
Floods have become more severe and frequent as a result of climate change around the world, posing a hazard to public safety and economic development. This study investigates the use of distributed hydrological models in flash flood risk management in a small watershed in Hazara, Pakistan, with the goal of improving Pakistan's early warning lead time. First, the HEC-HMS model was built using geographic data and the river network's structure, then calibrated and verified using eight high rainfall events from 2013. demonstrating that the HEC-HMS model could simulate floods in the research area Second, given that rainfall and flood events have happened, this paper proposes an analysis approach for a flood forecasting and warning system, as well as criteria for sending urban-stream flash flood alerts based on rainfall, in order to provide sufficient lead time. The DEMs (digital elevation models) of the research regions were processed using HEC-Geo HMS, an ArcView GIS tool for catchment delineation, terrain pre-processing, and basin processing. The model was calibrated and verified using previously observed data. The proposed flood prediction and risk reduction methodology is nonstructural. The Hydrologic Modeling System (HEC-HMS), which provides a sufficient lead time forecast and computes the runoff/stage threshold conditions, is at the heart of the flood warning application. For flood risk assessment, data from the Pakistan Meteorological Department (PMD) is entered into a hydro-meteorological database and then into the HEC-HMS. A server-client application was utilised to visualise the real-time flood scenario and send out an early warning message. The outcomes of this study will be used to develop flood validation measures in the Hazara stream watershed to deal with potential flash floods.
\end{abstract}

Keywords: HEC-HMS, hydrological modeling, flash flood risk management, Hazara watershed Pakistan
Volume 6 Issue I - 2022

\author{
Muhammad Umer Nadeem,' Zeeshan \\ Waheed, ${ }^{4}$ Abdul Mannan Ghaffar, ${ }^{2}$ \\ Muhammad Mashood Javaid, ${ }^{3}$ Ameer Hamza, ${ }^{2}$ \\ Zain Ayub,' Muhammad Asim Nawaz,' \\ Wajahat Waseem, ${ }^{3}$ Malik Faisal Hameed, ${ }^{3}$ Ali \\ Zeeshan, ${ }^{2}$ Saliha Qamar, ${ }^{2}$ Kainat Masood ${ }^{3}$ \\ 'Department of Land and Water Conservation Engineering, \\ Faculty of Agricultural Engineering and Technology, PMAS-Arid \\ Agriculture University, Rawalpindi 46000, Pakistan \\ ${ }^{2}$ Department of Farm Machinery and Precision Engineering, \\ Faculty of Agricultural Engineering and Technology, PMAS Arid \\ Agricultural University, Rawalpindi 46000, Pakistan \\ ${ }^{3}$ Department of Energy system Engineering, Faculty of \\ Agricultural Engineering and Technology, PMAS Arid Agricultural \\ University, Rawalpindi 46000, Pakistan \\ ${ }^{4}$ Department of Structure and Environmental Engineering, \\ Faculty of Agricultural Engineering and Technology, PMAS Arid \\ Agricultural University, Rawalpindi 46000, Pakistan
}

\section{Correspondence: Muhammad Mashood Javaid, Department of Energy system Engineering, Faculty of Agricultural Engineering and Technology, PMAS Arid Agricultural University, Rawalpindi 46000, Pakistan,Email Mashj@hestan.com}

Received: January 10, 2022 | Published: January 17, 2022

\section{Introduction}

Many of the ideological debates in pragmatic human ecology, critical realism political ecology, and the poststructural social nature thesis can be studied through flood danger research in the Hazara watershed. These discussions centre on the practical aspects of flood prevention, as well as the hazard-scape idea, which is founded on the geography concept of environment. Flash floods are typically caused by heavy rain, but they can also be caused by dam failures, levee failures, or even ice jams in rivers during the winter and spring months. ${ }^{1}$ As the world's population increases, so does the risk of flash flooding. Runoff from impervious surfaces, such as concrete or compacted bare soils, contributes a significant volume of runoff, which can quickly damage roads and structures. ${ }^{2}$ As a result, the intensity of the rainfall event and the spatial distribution of land cover have a major impact on the watershed's hydrologic response. As a result, flash floods should be examined at both spatial and temporal scales to identify the exact response time of the watershed (concentration time).

The primary purpose of a flood forecasting system is to reduce the loss of life, property, and business by providing accurate warnings with ample lead time to users and emergency managers specially in Pakistan. ${ }^{3}$ The lead time is determined by the hydrologic model's efficiency and forecast quality. The only way to combine meteorological forecasts with hydrologic models in flood forecasting systems is to use forecasted hydro-meteorological data. ${ }^{4}$ In meteorological forecasting, regional numerical weather prediction models are used. There are many different types of hydrologic models, and their use varies depending on the sort of findings needed and the availability of hydrological data. The hydrological processes can be characterised empirically, intellectually, or physically, and the deterministic models can be classified based on whether they provide a lumped or distributed description of the examined area.

The HEC-HMS Model was utilised for runoff prediction in this study since it is vital for early flood warning. As a substitute for HEC-1, the US Corps of Engineers' Hydrologic Engineering Center (HEC) took the initiative. HEC-HMS enhances HEC-1's capabilities by allowing for distributed modelling and continuous simulation. The application of HEC-HMS, as well as the precision of calibration and validation, are crucial for the development of EFWS. The HEC-HMS model can simulate precipitation-runoff and routing mechanisms in both natural and controlled environments ${ }^{5}$ HEC-HMS is a straightforward conceptual model that has been successfully developed by a number of academics throughout the world. It is superior for peak flow simulation than the Revitalized Flood Hydrograph model because of the semi-distributed modelling idea. Because the soil moisture accounting model, which is based on the natural hydrological cycle in natural catchments, is regarded as a suitable model for rural catchments. When the semi-distributed model HEC-HMS and the fully-distributed model Basin Pollution Calculation Center (BPCC) were used to simulate the rainfall runoff process in the mountain area, the findings revealed a little disagreement between the two models.

In Arc-GIS 10.7.1, the Digital Elevation Model(DEM) of the Hazara watershed was created using SRTM 90m (Shuttle Radar Topographic Mission). Aerial rainfall is calculated utilising the Thiessen polygon method (by multiplying gauge weights of metrological stations with situ-gauge rainfall). Arc-GIS was also used to demarcate the Hazara watershed. Diva-GIS is used to download Land Use/Land Cover (LU/ LC) data. All maps and applicable formulas from prior studies are utilised to generate the parameters. Finally, the watershed is identified 
and then integrated into the HEC-HMS model for calibration and validation. Time of concentration, curve number, lag time, and area of watershed is calculated from suitable formulas and maps devolved in this study.

GIS (geographic information systems) has become an important part of hydrologic studies due to the spatial character of the causes and precipitation that affect hydrologic processes. In the parameterization of distributed hydrologic models, the usage of geographic information systems (GIS) is crucial. To avoid gross simplifications caused by parameter lumping at the river basin scale during representation, this is done. GIS applications are utilised to extract hydrologic information such as flow direction, flow accumulation, watershed boundaries, and stream networks from a DEM (digital elevation model). To assess the model's performance, this study used GIS and HEC-HMS.

\section{Materials and methods}

\section{Study area}

Hazara stream sub-watershed is located in Pakistan city at Latitude: $35^{\circ} 14^{\prime} 60.00^{\prime \prime} \mathrm{N}$, Longitude: $73^{\circ} 29^{\prime}$ 59.99" Containing the area of $340 \mathrm{~km}^{2}$. It is a region of Pakistan's Khyber Pakhtunkhwa province located in the northeast. It is situated to the east of the Indus River. The nine rainfall stations are present in Hazara watershed which is used to calculate aerial rainfall of stations Figure 1.

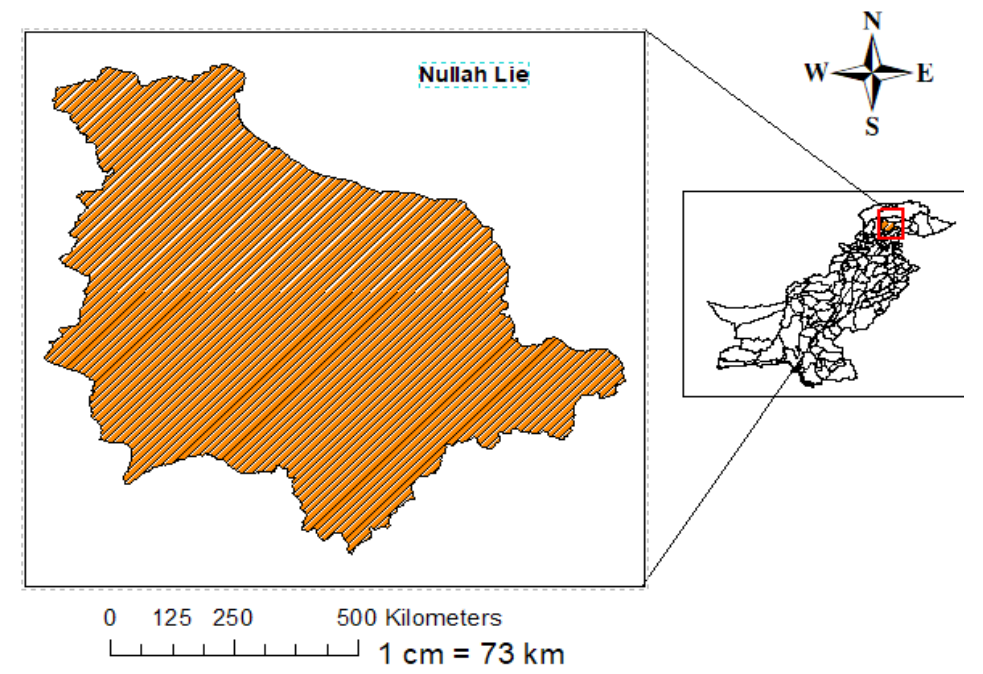

Figure I Map of Hazara (study area).

\section{Thiessen polygon}

In the Thiessen polygon, there is only a single point input feature. The associated point of a Thiessen polygon is closer to any point within it than any other point input feature. Perpendicular bisectors are generated for each triangle edge to construct the edges of the Thiessen polygons. ${ }^{6}$ Where the bisectors connect determines where the Thiessen polygon vertices are placed. The coordinate system is first set to WGS1984. The shapefile for Pakistan can be downloaded from the DIVA-GIS website. The vector data of metrological stations is acquired from the PMD website (Pakistan metrological department website), and the files are then imported into ArcGIS. Thiessen polygon is made in ArcGIS after that their weighted rainfall is measured which is known as Aerial Rainfall Figure 2, Table 1.

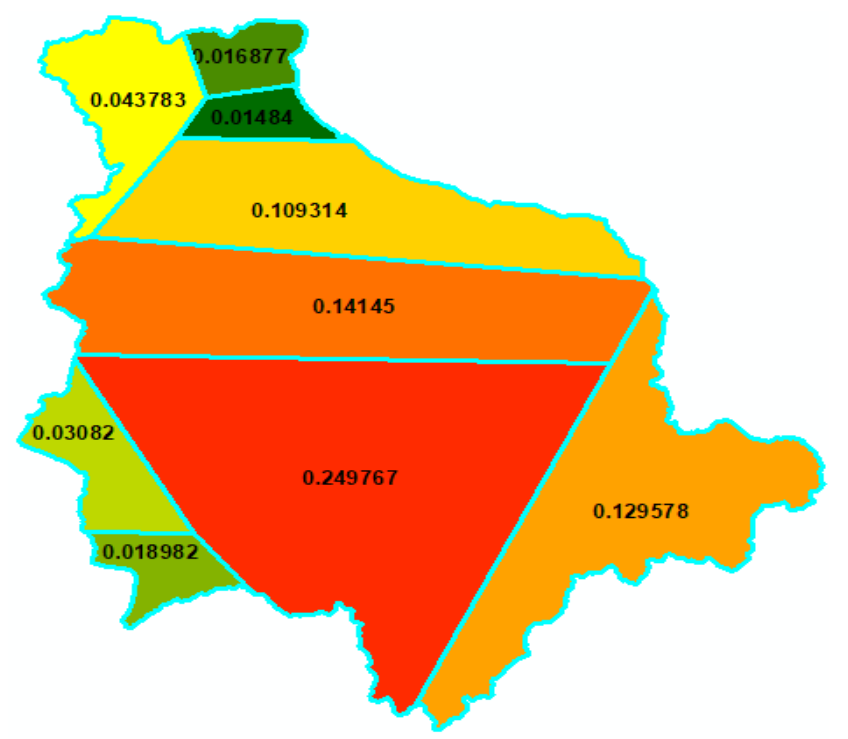

Figure 2 Thiessen Polygon of study area. 
Table I Gauge weight calculation of study area

\begin{tabular}{llllllll}
\hline OBJECTID* & Shape* & Input_FID & $\begin{array}{l}\text { Shape } \\
\text { Length }(\mathbf{m})\end{array}$ & $\begin{array}{l}\text { Shape } \\
\text { Area }\left(\mathbf{m}^{2}\right)\end{array}$ & Area $\left(\mathbf{m}^{2}\right)$ & Parameter $(\mathbf{m}) \begin{array}{l}\text { weighted } \\
\text { area }\left(\mathbf{m}^{2}\right)\end{array}$ \\
\hline 1 & Polygon & 4 & 2.4 & 0.2 & $2.53 \mathrm{E}+09$ & 237700.1 & 0.331521 \\
2 & Polygon & 8 & 2.4 & 0.1 & $1.31 \mathrm{E}+09$ & 249240.5 & 0.172167 \\
3 & Polygon & 7 & 0.6 & 0 & $1.69 \mathrm{E}+08$ & 56305.4 & 0.022205 \\
4 & Polygon & 3 & 0.9 & 0 & $3.12 \mathrm{E}+08$ & 93664.2 & 0.040924 \\
5 & Polygon & 1 & 2.2 & 0.1 & $1.43 \mathrm{E}+09$ & 203963.3 & 0.187086 \\
6 & Polygon & 0 & 0.8 & 0 & $1.92 \mathrm{E}+08$ & 74402.7 & 0.025234 \\
7 & Polygon & 6 & 1.2 & 0 & $4.4 \mathrm{E}+08$ & 123391.2 & 0.057667 \\
8 & Polygon & 5 & 1.9 & 0.1 & $1.09 \mathrm{E}+09$ & 180952 & 0.143663 \\
9 & Polygon & 2 & 0.7 & 0 & $1.49 \mathrm{E}+08$ & 62096.4 & 0.019534 \\
\hline
\end{tabular}

\section{Digital elevation model}

A digital elevation model (DEM) is a three-dimensional computer graphical representation of elevation data that is used to depict terrain on a planet, moon, or asteroid. The term "global DEM" refers to a discrete global grid. DEMs are the most common substrate for digitally produced relief maps, and they're often utilised in GIS systems. ${ }^{7}$ DSMs and DTMs that only provide height information without any additional surface characteristics are referred to as DEMs. In Arc-GIS 10.7, the Hazara watershed Digital Elevation Model (DEM) is based on SRTM 90m (Shuttle Radar Topographic Mission) Figure 3.

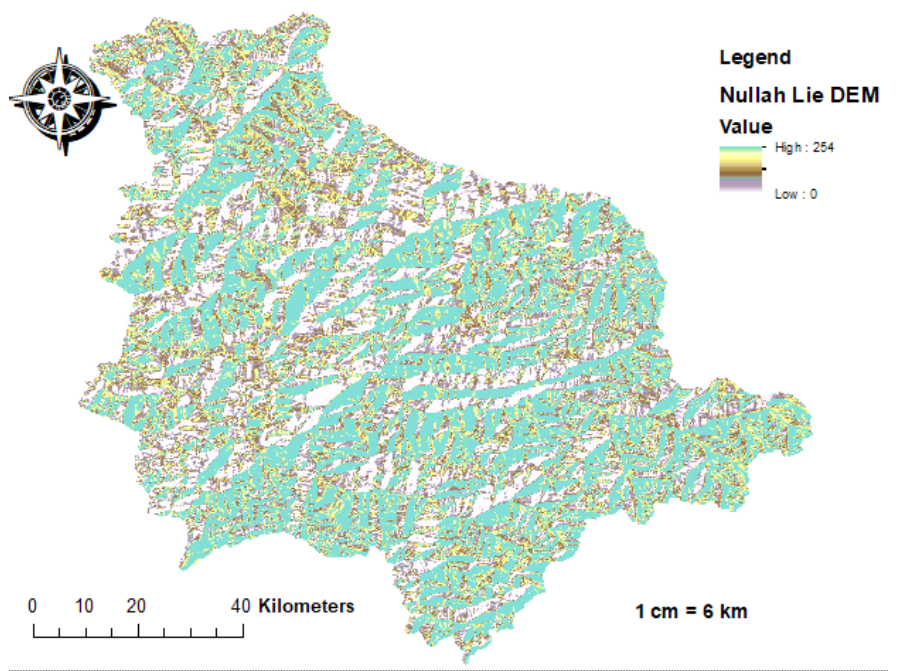

Figure 3 Digital Elevation model (DEM).

\section{Delineation}

Watershed delineation is one of the most common activities in hydrologic and environmental study. Watersheds can be estimated automatically using GIS technology employing digital elevation models (DEMs), which provide a fair representation of the topography. Since the early 1980s, automated watershed delineation techniques have been available and used in a number of GIS systems and specialised applications. These techniques work regardless of DEM quality and have become more popular as better resolution DEMs have become available, allowing for more detailed topographical depiction and analysis. The growth of desktop computing power, which allows complex procedures to be completed locally and swiftly enough, is another element contributing to the attraction of these techniques.
These two considerations, together with a growing industry focus on drainage basin solutions, are putting more pressure on automated systems to deliver results quickly Figure 4.

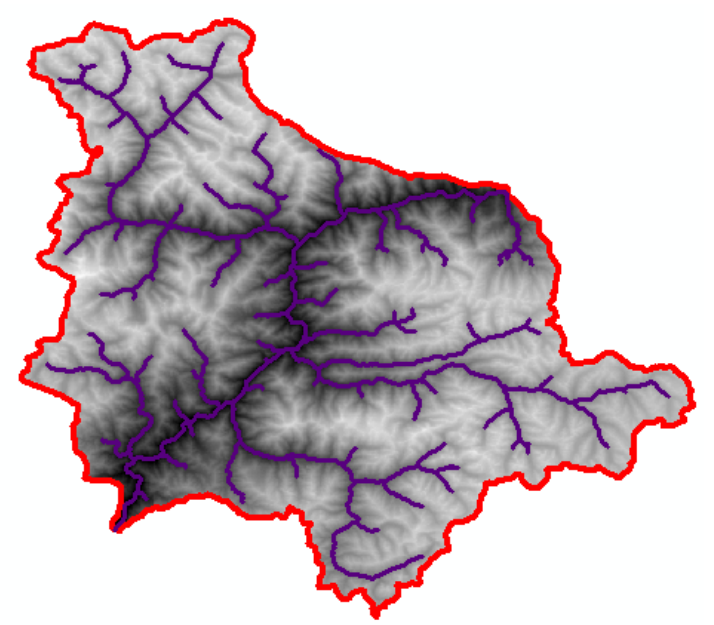

Figure 4 Delineated Basin of study area

\section{Land use land cover (LU/LC)}

The classification of raw satellite data into "land use and land cover" groupings yields Land Use and Land Cover (LULC) data. The way humans use the land and engage in socioeconomic activities is referred to as land use. Land use refers to how people use the landscape, such as whether it is developed, used for agricultural, or a combination of the two. Land cover is the physical material that covers the earth's surface. The amount of forest, wetlands, impermeable surfaces, agricultural, and other land and water types that cover a region is shown by land cover data. Land cover data can aid our understanding of the terrain and how humans interact with it Figure $5 .^{8}$

\section{HEC-HMS calibrations}

HEC-HMS is a computer programme that simulates precipitationrunoff processes in dendritic drainage basins. ${ }^{9}$ It's meant to be used in a variety of settings and to solve as many problems as possible. Water supply and flood hydrology in large river basins, as well as local urban or natural watershed runoff, are all covered Figure $6{ }^{10,11}$ The program's hydrographs are used either directly or in conjunction with 
other software in studies of water availability, urban drainage, flow forecasting, future urbanisation impact, reservoir spillway design, flood damage reduction, floodplain regulation, and system operation. Two sub-basins were generated having different areas and different parameters calculated by suitable formulas and methods Figure $7,8{ }^{12-}$ 14,1

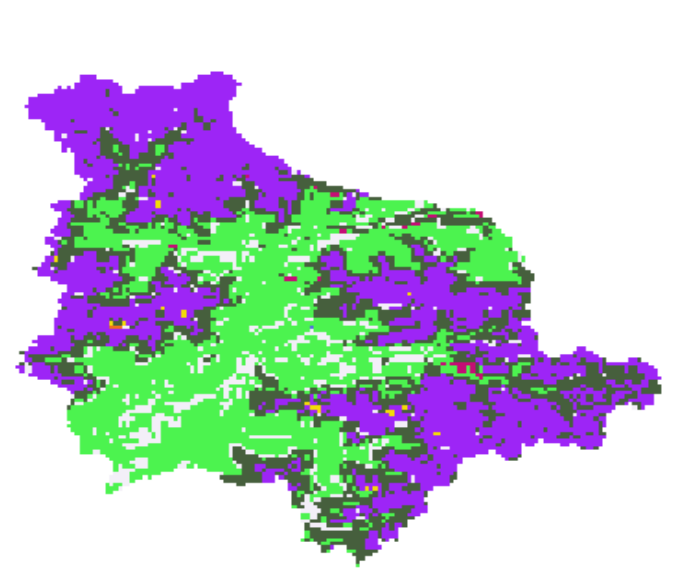

Figure 5 Landcover data

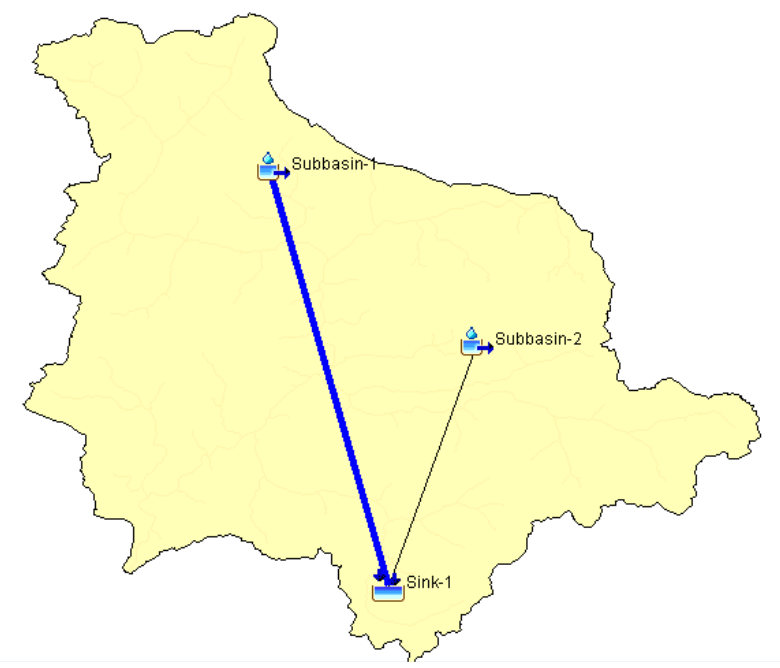

Figure 6 HEC-HMS Calibration model.

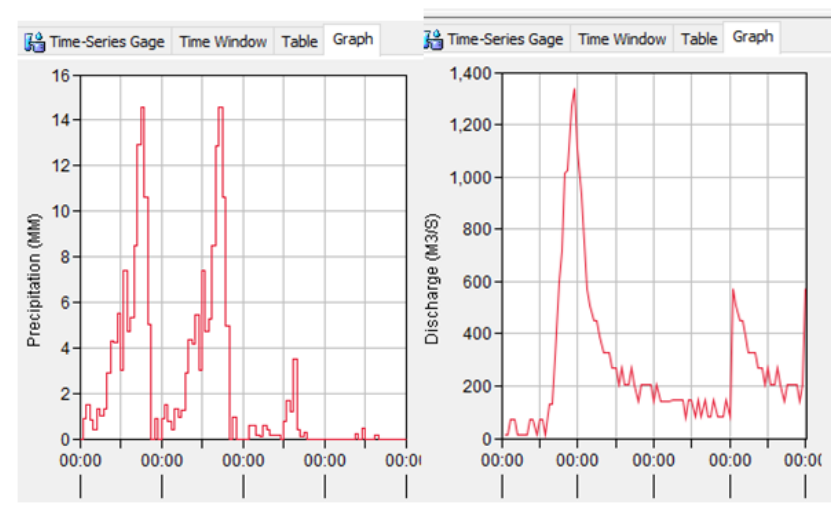

Fig no 7, 8 Precipitation and discharge hydrograph.

\section{Results and discussion}

As stated in the emergence, each component of HEC-HMS replicates a different aspect of the precipitation-runoff process within a sub-basin of the basin.A set of parameters that indicate the component's unique properties, as well as quantitative properties that describe the physical processes, are essential for component representation (Hazara watershed). The standardized model parameters of each of the components represented in this model are shown in Table 1 and 2. Aside from the preset sub-areas, parameters were calibrated sequentially by adjusting their values until a good agreement between the observed and simulated hydrographs was attained Table 3.

Table 2 Final summary of HEC-HMS calibrations

\begin{tabular}{lllll}
\hline $\begin{array}{l}\text { Hydrological } \\
\text { element }\end{array}$ & $\begin{array}{l}\text { Drainage } \\
\left(\mathbf{K m}^{2}\right)\end{array}$ & $\begin{array}{l}\text { peak } \\
\text { Discharge } \\
\left(\mathbf{m}^{3} / \mathbf{s}\right)\end{array}$ & time of Peak & $\begin{array}{l}\text { Volume } \\
\left(\mathbf{m m}^{3}\right)\end{array}$ \\
\hline Subbasin-I & 239.5 & 369.4 & |4Jan20|3, 19:00 & 45.2 \\
Subbasin-2 & 240 & 293.8 & |4Jan2013, 19:00 & 32.66 \\
Reach-I & 239.5 & 340.7 & 14Jan2013, 20:00 & 45.2 \\
Sink-I & 479.5 & 624.9 & |4Jan2013, 19:00 & 38.93 \\
\hline
\end{tabular}

Table 3 Calibrated \& validated result of HEC-HMS run model

\begin{tabular}{|c|c|c|c|}
\hline Date & Time & inflow $\left(\mathrm{m}^{3} / \mathrm{sec}\right)$ & outflow $\left(\mathrm{m}^{3} / \mathrm{sec}\right)$ \\
\hline 13-Jan-13 & $0: 00$ & 0 & 0 \\
\hline 13-Jan-13 & $\mathrm{I}: 00$ & 0 & 0 \\
\hline 13-Jan-13 & $2: 00$ & 0 & 0 \\
\hline I3-Jan-13 & $3: 00$ & 0 & 0 \\
\hline I3-Jan-I3 & $4: 00$ & 0 & 0 \\
\hline |3-Jan-13 & 5:00 & 0 & 0 \\
\hline 13-Jan-13 & $6: 00$ & 0 & 0 \\
\hline 13-Jan-13 & 7:00 & 0 & 0 \\
\hline 13-Jan-13 & $8: 00$ & 0 & 0 \\
\hline 13-Jan-13 & $9: 00$ & 0 & 0 \\
\hline 13-Jan-13 & $10: 00$ & 0 & 0 \\
\hline |3-Jan-13 & II:00 & 0 & 0 \\
\hline 13-Jan-13 & $12: 00$ & 0 & 0 \\
\hline 13-Jan-13 & $13: 00$ & 0 & 0 \\
\hline 13-Jan-13 & $14: 00$ & 0 & 0 \\
\hline 13-Jan-13 & $15: 00$ & 0 & 0 \\
\hline 13-Jan-13 & $16: 00$ & 0 & 0 \\
\hline 13-Jan-13 & $17: 00$ & 0 & 0 \\
\hline 13-Jan-13 & $18: 00$ & 1.2 & 0.3 \\
\hline 13-Jan-13 & $19: 00$ & 26.2 & 6.7 \\
\hline I3-Jan- 13 & $20: 00$ & 64 & 30.4 \\
\hline 13-Jan-13 & $21: 00$ & 71.1 & 57.9 \\
\hline 13-Jan-13 & $22: 00$ & 40.5 & 61 \\
\hline 13-Jan-13 & $23: 00$ & 18 & 40 \\
\hline I4-Jan- I3 & $0: 00$ & 9.3 & 21.1 \\
\hline 14-Jan-13 & $\mathrm{I}: 00$ & 7.6 & 11.6 \\
\hline 14-Jan-13 & $2: 00$ & 13.3 & 9.8 \\
\hline
\end{tabular}


Table Continued...

\begin{tabular}{|c|c|c|c|}
\hline Date & Time & inflow $\left(\mathrm{m}^{3} / \mathrm{sec}\right)$ & outflow $\left(\mathrm{m}^{3} / \mathrm{sec}\right)$ \\
\hline |4-Jan- | 3 & $3: 00$ & 13.9 & 12.6 \\
\hline |4-Jan- 13 & $4: 00$ & 9.7 & 12.6 \\
\hline |4-Jan-| 3 & $5: 00$ & 11.9 & 10.9 \\
\hline |4-Jan- I 3 & $6: 00$ & 14.6 & 12.3 \\
\hline |4-Jan-13 & 7:00 & 15.9 & 14.4 \\
\hline |4-Jan-13 & $8: 00$ & 27.6 & 18.3 \\
\hline |4-Jan- I 3 & $9: 00$ & 48.9 & 30.4 \\
\hline I4-Jan-13 & $10: 00$ & 64.6 & 48.3 \\
\hline |4-Jan- I 3 & II:00 & 81.6 & 64.7 \\
\hline |4-Jan- I 3 & $12: 00$ & 79.3 & 77.2 \\
\hline |4-Jan-| 3 & $13: 00$ & 103.1 & 84.3 \\
\hline |4-Jan-13 & $14: 00$ & 119.4 & 102.5 \\
\hline |4-Jan- I 3 & $15: 00$ & 117.6 & II5.I \\
\hline |4-Jan-| 3 & $16: 00$ & 156.5 & 126 \\
\hline |4-Jan-| 3 & $17: 00$ & 247.3 & 170.4 \\
\hline I4-Jan-13 & $18: 00$ & 348.3 & 252.9 \\
\hline |4-Jan-| 3 & $19: 00$ & 369.4 & 331.2 \\
\hline |4-Jan-| 3 & $20: 00$ & 283.4 & 340.7 \\
\hline |4-Jan- I 3 & $21: 00$ & 142.5 & 264.1 \\
\hline |4-Jan- | 3 & $22: 00$ & 60.2 & 151.6 \\
\hline I4-Jan-13 & $23: 00$ & 29.3 & 74.2 \\
\hline I5-Jan-13 & $0: 00$ & 9.6 & 35.1 \\
\hline I5-Jan-| 3 & $\mathrm{I}: 00$ & 3 & 14 \\
\hline I5-Jan- I 3 & $2: 00$ & 0.8 & 5 \\
\hline I5-Jan-| 3 & $3: 00$ & 7.6 & 3.3 \\
\hline I5-Jan-| 3 & $4: 00$ & 15.7 & 8.5 \\
\hline I5-Jan-13 & 5:00 & 12.6 & 13.3 \\
\hline I5-Jan-13 & $6: 00$ & 7.1 & 11.5 \\
\hline |5-Jan-| 3 & $7: 00$ & II.3 & 9.1 \\
\hline I5-Jan-| 3 & $8: 00$ & 14.8 & 11.6 \\
\hline I5-Jan-| 3 & $9: 00$ & 10.8 & 13.2 \\
\hline I5-Jan-I 3 & $10: 00$ & 6.7 & 10.4 \\
\hline 15-Jan-13 & II:00 & 5.5 & 7.3 \\
\hline I5-Jan-I 3 & $12: 00$ & 3.4 & 5.4 \\
\hline I5-Jan-| 3 & $13: 00$ & 10.9 & 5.6 \\
\hline I5-Jan- I 3 & $14: 00$ & 32.5 & 14.6 \\
\hline I5-Jan-| 3 & $15: 00$ & 42.4 & 30.7 \\
\hline I5-Jan-| 3 & $16: 00$ & 72.2 & 46.6 \\
\hline I5-Jan- $\mid 3$ & $17: 00$ & 64 & 64.4 \\
\hline I5-Jan-I3 & $18: 00$ & 26.9 & 55.5 \\
\hline I5-Jan-| 3 & $19: 00$ & 14.2 & 30.5 \\
\hline
\end{tabular}

Table Continued...

\begin{tabular}{|c|c|c|c|}
\hline Date & Time & inflow $\left(\mathrm{m}^{3} / \mathrm{sec}\right)$ & outflow $\left(\mathrm{m}^{3} / \mathrm{sec}\right)$ \\
\hline I5-Jan-13 & $20: 00$ & 7.6 & 16.4 \\
\hline 15-Jan-13 & $21: 00$ & 2.5 & 8.4 \\
\hline 15-Jan-13 & $22: 00$ & 0.8 & 3.5 \\
\hline 15-Jan-13 & $23: 00$ & 0.2 & 1.3 \\
\hline 16-Jan-13 & $0: 00$ & 0.1 & 0.4 \\
\hline 16-Jan-13 & $\mathrm{I}: 00$ & 0 & 0.1 \\
\hline I6-Jan-13 & $2: 00$ & 0 & 0 \\
\hline 16-Jan-13 & $3: 00$ & 0 & 0 \\
\hline 16-Jan-13 & $4: 00$ & 0 & 0 \\
\hline 16-Jan-13 & $5: 00$ & 0 & 0 \\
\hline 16-Jan-13 & $6: 00$ & 0 & 0 \\
\hline 16-Jan-13 & 7:00 & 0 & 0 \\
\hline 16-Jan-13 & $8: 00$ & 0 & 0 \\
\hline 16-Jan-13 & $9: 00$ & 0 & 0 \\
\hline 16-Jan-13 & $10: 00$ & 2.5 & 0.6 \\
\hline 16-Jan-13 & $11: 00$ & 2.7 & 2.1 \\
\hline 16-Jan-13 & $12: 00$ & 7 & 3.5 \\
\hline 16-Jan-13 & $13: 00$ & 6.9 & 6.2 \\
\hline I6-Jan-13 & $14: 00$ & 2.3 & 5.7 \\
\hline 16-Jan-13 & $15: 00$ & 0.8 & 2.7 \\
\hline 16-Jan-13 & $16: 00$ & 2.2 & 1.6 \\
\hline I6-Jan-13 & $17: 00$ & 2.2 & 2 \\
\hline 16-Jan-13 & $18: 00$ & 0.7 & 1.8 \\
\hline 16-Jan-13 & 19:00 & 0.2 & 0.9 \\
\hline I6-Jan-13 & $20: 00$ & 0.1 & 0.3 \\
\hline 16-Jan-13 & $21: 00$ & 0 & 0.1 \\
\hline 16-Jan-13 & $22: 00$ & 0 & 0 \\
\hline 16-Jan-13 & $23: 00$ & 0 & 0 \\
\hline 17-Jan-13 & $0: 00$ & 0 & 0 \\
\hline
\end{tabular}

Final calibrations of is given below of sub-basin 1 and subbasin 2 , reach1 and reach 2 Figure 9.

\section{Run model parameters}

Sub-basin 1 area: $240 \mathrm{~km}^{2}$

Sub-basin 2 area: $239.5 \mathrm{~km}^{2}$

Muskingum; K $(\mathrm{HR})=1$

Muskingum; $\mathrm{X}=0.2$

Lag time $=60$

Curve Number $=45$

Impervious $=0 \%$ Figure $10-14$.

The simulated and observed peak discharges occurred on the same day, with a maximum time difference of one hour, which is acceptable for flood predictions, as can be seen in the graphs above. 


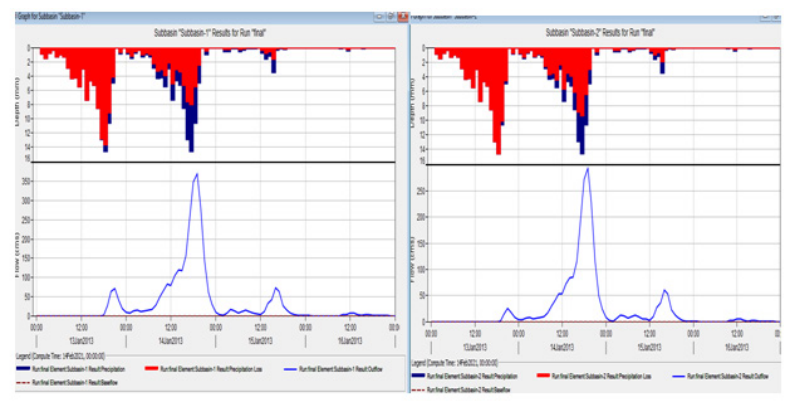

Figure 9 Results of sub-basin I, 2.

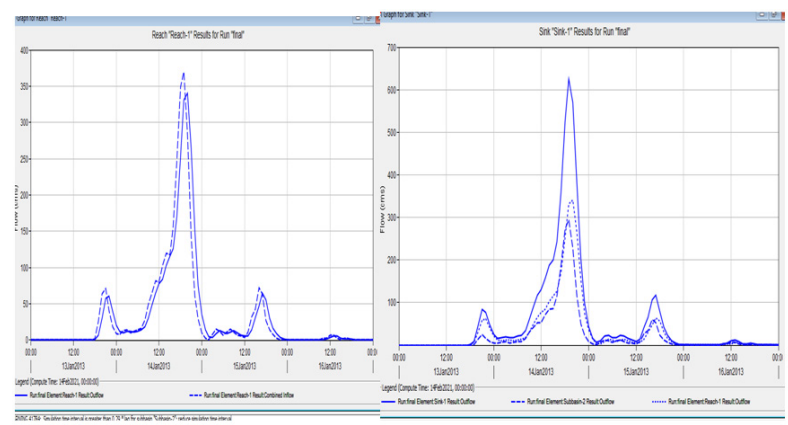

Figure I0, I I Final result of HEC-HMS calibrations of reach I and sink I respectively.

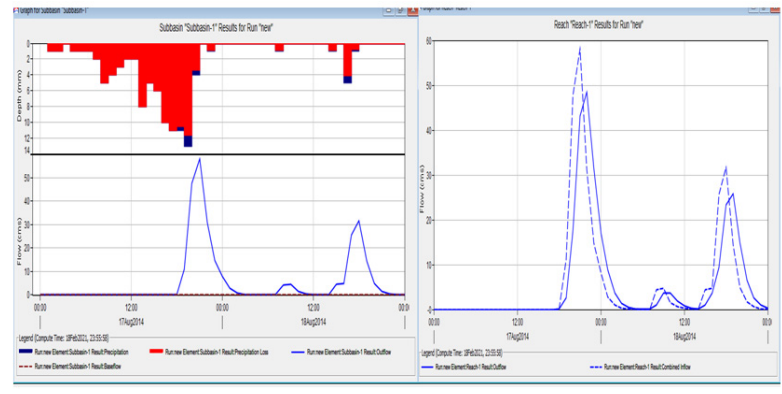

Figure 12, I 3 Sub-basin and reach I results.

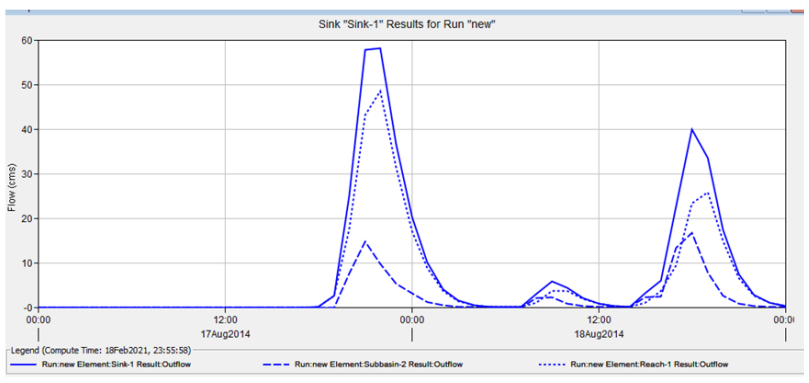

Figure I 4 Final result of sink of run model.

\section{Conclusion}

The model correctly predicted peak discharge based on known historical flood data, as seen in the findings above. The flood's size and timing were both fairly accurate. This demonstrates that the HECHMS is suitable for the catchments in question. We can draw from the findings that the complexity of the model structure has no influence on its applicability or efficiency. Despite its simplicity, the HEC-HMS framework is an effective flood forecasting tool. More testing of the HEC-HMS should be encouraged in order to determine its suitability for Pakistani catchments.

\section{Acknowledgments}

The author would like to thank Pakistan metrological department (PMD) and water and Power Development Authority (WAPDA) for providing the discharge and rainfall data used in this study.

\section{Conflicts of interest}

The authors declares no conflict of interest.

\section{References}

1. Oleyiblo, James Oloche, Zhi Jia Li. Application of HEC-HMS for Flood Forecasting in Misai and Wan'an Catchments in China." Water Science and Engineering. 2010;3(1):14-22.

2. Rehman, Abdul, Hengyun Ma, et al. "Towards Environmental Sustainability: Devolving the Influence of Carbon Dioxide Emission to Population Growth, Climate Change, Forestry, Livestock and Crops Production in Pakistan.” Ecological Indicators. 2021;125:107460.

3. Ali Muhammad, Sher Jamal Khan, Irfan Aslam, et al. Simulation of the Impacts of Land-Use Change on Surface Runoff of Lai Nullah Basin in Islamabad, Pakistan. Landscape and Urban Planning. 2011;102(4):271279.

4. Zhang, Hui Lan, Yu Jie Wang. Quantitative Comparison of Semi- and Fully-Distributed Hydrologic Models in Simulating Flood Hydrographs on a Mountain Watershed in Southwest China. Journal of Hydrodynamics. 2013;25(6):877-85.

5. Kwin, Chang Tak, Amin Talei, et al. Rainfall-Runoff Modeling Using Dynamic Evolving Neural Fuzzy Inference System with Online Learning." Procedia Engineering. 2016;154:1103-1109.

6. Herath MHBCW, NTS Wijesekera. Evaluation of HEC-HMS Model for Water Resources Management in Maha Oya Basin in Sri Lanka." Engineer: Journal of the Institution of Engineers, Sri Lanka. 2021;54(2):45.

7. Meng, Lin, Yuyu Zhou, et al. Photoperiod Decelerates the Advance of Spring Phenology of Six Deciduous Tree Species under Climate Warming." Global Change Biology. 2021;27(12):2914-127.

8. Hu, Shunfu, Prasanna Shrestha. Examine the Impact of Land Use and Land Cover Changes on Peak Discharges of a Watershed in the Midwestern United States Using the HEC-HMS Model." Papers in Applied Geography. 2020;6(2):101-18.

9. Castro, Cyndi V, David R, et al. GIS Preprocessing for Rapid Initialization of HEC-HMS Hydrological Basin Models Using Web-Based Data Services. Environmental Modelling and Software. 2020;130:104732.

10. Du, Jinkang, Li Qian, et al. Assessing the Effects of Urbanization on Annual Runoff and Flood Events Using an Integrated Hydrological Modeling System for Qinhuai River Basin, China. Journal of Hydrology. 2012;464-465:127-139.

11. Song, Xiao Meng, Fan Zhe Kong, et al. Application of Muskingum Routing Method with Variable Parameters in Ungauged Basin." Water Science and Engineering. 2011;4(1):1-12.

12. Azam, Muhammad, Hyung San Kim, et al. Development of Flood Alert Application in Mushim Stream Watershed Korea." International Journal of Disaster Risk Reduction. 2017;21:11-26.

13. Halwatura D, MMM Najim. Application of the HEC-HMS Model for Runoff Simulation in a Tropical Catchment." Environmental Modelling and Software. 2013;46:155-162.

14. Hasan Tanim, Ahad, Erfan Goharian. Developing a Hybrid Modeling and Multivariate Analysis Framework for Storm Surge and Runoff Interactions in Urban Coastal Flooding." Journal of Hydrology. 2021;595:125670.

15. Bhadoriya, Uday Pratap Singh, Ashok Mishra, et al. Implications of Climate Change on Water Storage and Filling Time of a Multipurpose Reservoir in India. Journal of Hydrology. 2020;590:125-542. 